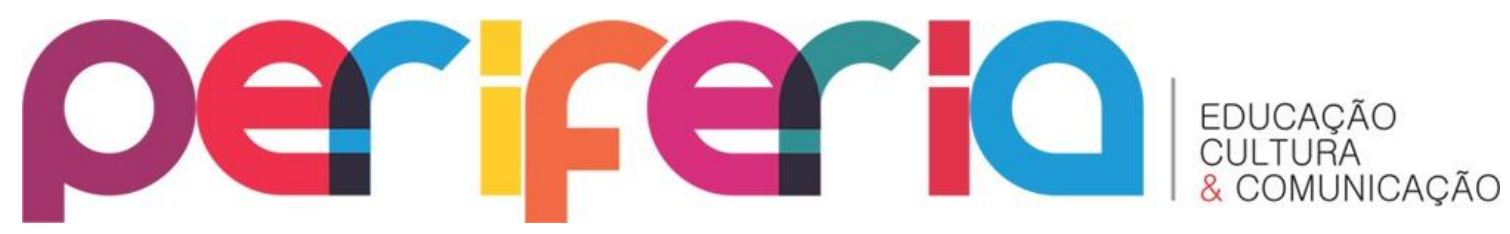

\title{
CAPOEIRA E ESCOLA: REFLEXÕES SOBRE A PROPOSTA DO PROGRAMA MAIS EDUCAÇÃO
}

\author{
Maria Alice Rezende Gonçalves ${ }^{1}$ \\ Universidade do Estado do Rio de Janeiro \\ Vinícius Oliveira Pereira ${ }^{2}$ \\ Universidade do Estado do Rio de Janeiro
}

\section{RESUMO}

O artigo discute a proposta do Programa Mais Educação para introdução da capoeira no espaço escolar. Tendo como pano de fundo um cenário de fortalecimento da etnicidade afro-brasileiro, debatemos em que medida a introdução da capoeira promovida pelo referido Programa pode colaborar para implementação da Lei 10639/03, responsável por incluir na LDBEN a temática "História e Cultura AfroBrasileira". Concluímos que apesar do reconhecimento da capoeira como patrimônio imaterial e da orientação para trabalhar com seus múltiplos aspectos, os sentidos atribuídos a ela no cotidiano escolar estão em disputa. Dessa forma, a capoeira pode ser pensada como cultura afro-brasileira, como patrimônio nacional ou ainda como simplesmente uma prática esportiva.

Palavras-Chaves: Cultura Afro-brasileira; Capoeira; Escola; Programa Mais Educação.

\section{CAPOEIRA AND SCHOOL: REFLECTION ABOUT THE PROGRAMA MAIS EDUCAÇÃO'S PROPOSAL}

\section{ABSTRACT}

The article discusses the proposal of the Programa Mais Educação for introduction of capoeira in school. Against the backdrop of a strengthening scenario of african-Brazilian ethnicity, discussing to what extent the introduction of capoeira promoted by the Program can contribute to implementation of Law 10639/03, responsible for including in LDBEN the theme "History and Culture Afro- Brazilian". We conclude that despite the recognition of capoeira as intangible heritage and orientation to work with its many aspects, the meanings attributed to it in school are in dispute. Thus, the capoeira can be thought of as african-Brazilian culture, as national heritage or as simply a sport.

Keywords: African-Brazilian Culture; Capoeira; Elementary School; Programa Mais Educação.

\footnotetext{
${ }^{1}$ Professora Associada do Departamento de Ciências Sociais e Educação da Faculdade de Educação da Universidade do Estado do Rio de Janeiro e Professora do Programa de Pós-Graduação em Educação, Cultura e Comunicação em Periferias Urbanas da UERJ (PPGECC/FEBF/UERJ). E-mail: marialicerezende@gmail.com

${ }^{2}$ Graduado em Pedagogia pela Universidade do Estado do Rio de Janeiro (2013). Atualmente cursa o mestrado no Programa de Pós-Graduação em Educação, Cultura e Comunicação em Periferias Urbanas da UERJ (PPGECC/FEBF/UERJ), com bolsa da Fundação de Amparo à Pesquisa do Estado do Rio de Janeiro - FAPERJ. E-mail: viniciusoliveirapereira@yahoo.com.br
} 


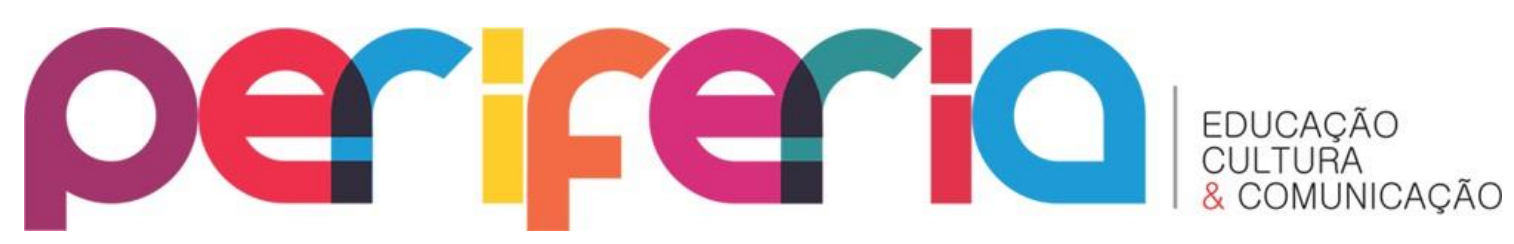

\section{CAPOEIRA E ESCOLA: REFLEXÕES SOBRE A PROPOSTA DO PROGRAMA MAIS EDUCAÇÃO}

\section{INTRODUÇÃO}

O artigo é uma derivação da pesquisa desenvolvida no Programa de Pósgraduação em Educação, Cultura e Comunicação da Universidade do Estado do Rio Janeiro. O mesmo se propõe a pensar o contexto contemporâneo de introdução da capoeira, entendida nesse artigo como uma manifestação de matriz africana, nas escolas municipais de Nova Iguaçu, município localizado na Região da Baixada Fluminense, no estado do Rio de Janeiro. A opção pela temática deve-se, entre outros fatores, ao fato de considerarmos a capoeira uma manifestação cultural que reúne uma série de elementos para a promoção da história e da cultura afro-brasileira no ambiente escolar, contribuindo, assim, para implementação da Lei 10639/03, responsável por modificar a Lei de Diretrizes e Bases da Educação Nacional (LDBEN) para incluir no currículo oficial da Rede de Ensino a obrigatoriedade da temática "História e Cultura Afro-Brasileira" ${ }^{3}$.

O contato mais próximo com a capoeira se deu em 2011, quando tivemos a oportunidade de coordenar e organizar um curso de educação continuada para capoeiristas de Maricá, município localizado no Estado do Rio de Janeiro. O curso, financiado pela prefeitura da mencionada cidade, foi organizado pelo Núcleo de Estudos Afro-brasileiros da Universidade do Estado do Rio de Janeiro, e visava discutir com capoeiristas alguns conteúdos e temas relacionados à História e Cultura Africana e Afro-brasileira, a fim de que elas e eles pudessem atuar nas escolas municipais de Maricá.

Em nota sobre a proposta de introdução dos capoeiristas no espaço escolar, retirada do site da prefeitura, é possível encontrar a seguinte afirmação: o objetivo não só é promover as rodas, mas também ensinar aos jovens a origem dessa manifestação

\footnotetext{
${ }^{3}$ No artigo "A capoeira no cotidiano escolar: tecendo caminhos para implementação da Lei 10639/03", discuto as possibilidades de articulação entre os valores civilizatórios afro-brasileiros presentes na capoeira e as disciplinas escolares.
} 


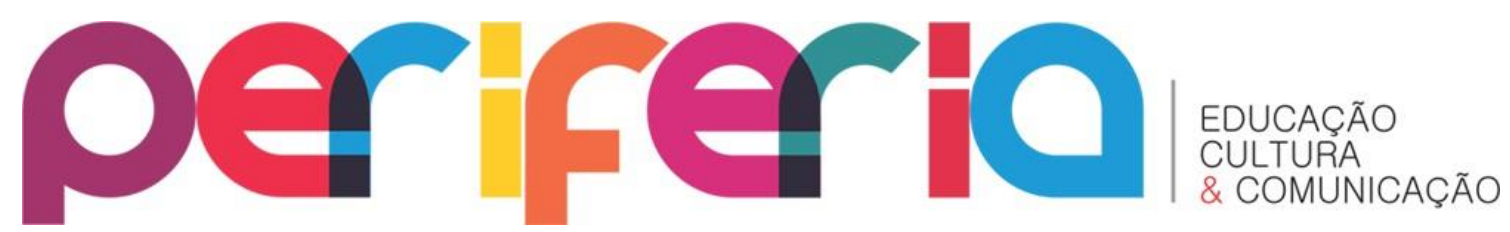

cultural". Essa informação permite dizer que o curso de extensão "Capacitando Capoeirista" se configurou como uma política institucional relevante para implementação da Lei 10639/2003, na medida em que atua na formação de educadores multiplicadores responsáveis por introduzir elementos da história e cultura afro-brasileira na escola.

Diferente do que ocorreu em Maricá, verifica-se que a entrada da capoeira nas escolas municipais de Nova Iguaçu ocorre, sobretudo, através do Programa Mais Educação, instituído pela Portaria Interministerial no 17/2007 e regulamentado pelo Decreto 7.083/10, que visa, de acordo com o Ministério da Educação, induzir a ampliação da jornada escolar e a organização curricular na perspectiva da Educação Integral $^{5}$. O aumento da oferta educativa nas escolas públicas se dá por meio de atividades optativas no contra turno escolar. Nas escolas localizadas em regiões consideradas urbanas, as atividades/oficinas são agrupadas em macro campos como: 1) Acompanhamento Pedagógico, 2) Comunicação, Uso de Mídias e Cultura Digital e Tecnológica, 3) Cultura Artes e Educação Patrimonial, 4) Educação Ambiental, 5) Desenvolvimento Sustentável e Economia Solidária e Criativa/Educação Econômica (Educação Financeira e Fiscal), 6) Esporte e Lazer, 7) Educação em Direitos Humanos e 8) Promoção da Saúde.

A capoeira, enquanto uma das atividades ofertadas pelo Programa Mais Educação, está alocada no macro campo Cultura, Artes e Educação Patrimonial, que reúne atividades destinadas ao:

Incentivo à produção artística e cultural, individual e coletiva dos estudantes como possibilidade de reconhecimento e recriação estética de si e do mundo, bem como da valorização às questões do patrimônio material e imaterial, produzido historicamente pela humanidade, no sentido de garantir processos de pertencimento ao local e à sua história. (Manual Operacional de Educação Integral, 2012, p. 17).

\footnotetext{
${ }^{4}$ Disponível em: < http://www.marica.rj.gov.br/?s=noticia\&n=1634> Acesso em 20 de agosto de 2014.

${ }^{5}$ De acordo com os dados fornecidos pela Secretaria Municipal de Educação de Nova Iguaçu, entre 2008 e 2014, 78 escolas da rede municipal de ensino ofertaram a capoeira como uma das atividades do Programa Mais Educação.
} 


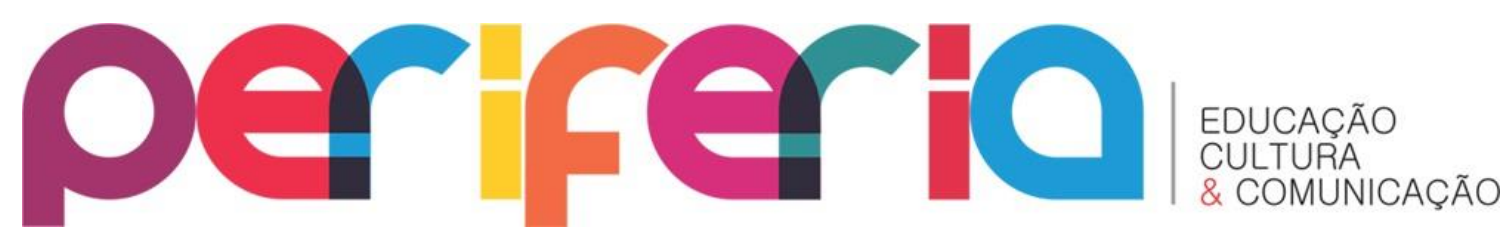

No decorrer do documento Manual Operacional de Educação Integral do Programa Mais Educação, responsável por orientar as atividades desenvolvidas na escola, podemos encontrar, ainda, a descrição dos objetivos de/para cada oficina. No espaço destinado a capoeira, tal documento sinaliza:

Incentivo à prática da capoeira como motivação para desenvolvimento cultural, social, intelectual, afetivo e emocional de crianças e adolescentes, enfatizando os seus aspectos culturais, físicos, éticos, estéticos e sociais, a origem e evolução da capoeira, seu histórico, fundamentos, rituais, músicas, cânticos, instrumentos, jogo e roda e seus mestres. (Manual Operacional de Educação Integral, 2012, p. 17).

A abordagem da capoeira proposta pelo mencionado documento evidencia uma mudança de paradigma em relação ao tratamento ofertado pelo Estado Brasileiro - representado na figura do Ministério da Educação - à capoeira, em particular, e às manifestações da cultura afro-brasileira, de modo geral. Se antes a história da capoeira foi marcada por negligências e perseguição, na contemporaneidade ela é ofertada como uma política curricular no ambiente escolar, que visa, como consta em seu objetivo, trabalhar com aspectos de sua história, origem e cultura. Apesar das contradições e dos limites impostos ao trabalho com a capoeira no espaço escolar, não podemos nos furtar a dizer que sua atual inserção na escola expressa e, ao mesmo tempo, é expressão de uma nova tessitura social, marcada pela demanda por reconhecimento dos patrimônios, símbolos culturais e histórias dos diferentes grupos étnicos que constituem a sociedade brasileira, e, consequentemente, o espaço escolar.

\section{CAPOEIRA E ESCOLA: BREVE DIGRESSÃO SOBRE O MITO FUNDADOR DO BRASIL}

Ao nos debruçarmos mais atentamente sobre as narrativas que constituem a(s) história(s) da/sobre capoeira, torna-se possível apreender elementos que evidenciam uma tentativa de aproximação entre tal manifestação cultural e os espaços educativos, mais especificamente a escola. Referimo-nos à tentativa de tornar a capoeira a ginástica brasileira: 


\section{periferio}

Embora colocados como criminosos, os capoeiristas tiveram uma recuperação social promovida pela "vertente nacionalista da belle époque", que buscava defender a capoeira como ginástica brasileira. Nesse sentido, Coelho Neto "representou o ponto alto da versão que defendia a transformação da capoeira em esporte nacional". [...] Coelho Neto não apenas realça as qualidades ginásticas da capoeira. Ele a celebra como a verdadeira educação física do Brasil, que deve ser ensinada nas escolas, quartéis, lares, em quaisquer lugares onde a instrução seja importante. (Dossiê - Inventário para o Registro e Salvaguarda da Capoeira como Patrimônio Cultural do Brasil, 2007, p. 18).

O projeto, que visava instituir a obrigatoriedade do ensino da capoeira em escolas e quartéis, não chegou a ser aprovado. No entanto, o movimento narrado acima oferece elementos para pensar as especificidades dos contextos e propostas de aproximação entre a capoeira e a escola. O processo encabeçado por Coelho Neto se deu, como mencionado na citação acima, nas primeiras décadas do século XX. 0 referido período se destaca por ser considerado um dos mais efervescentes momentos de debate sobre a construção de um projeto nacional para o Brasil, bem como de uma identidade nacional.

A análise mais detalhada das movimentações que teciam a conjuntura das três primeiras décadas do século passado leva ao reconhecimento da importante contribuição de Benedict Anderson para o estudo sobre nacionalismo, Estado-nação e a construção do projeto nacional. Ao cunhar o termo comunidades imaginadas, Anderson (1989) visibiliza os aspectos histórico-sociais responsáveis pela constituição do sentimento de nacionalidade, e aponta como tais elementos são utilizados para projetar uma imagem da nação. Tendo em vista esta perspectiva, é possível pensar a educação como um desses recursos, na medida em que colabora para a construção e legitimação dos Estados nacionais, ou, como sugerem as pesquisas de Anderson, das comunidades imaginadas.

Benedict Anderson centra-se na importância dos elementos culturais para construção dos Estados nacionais, pois o autor reconhece a necessidade dos símbolos que sustentam a comunidade imaginada dialogarem, minimamente, com a realidade 


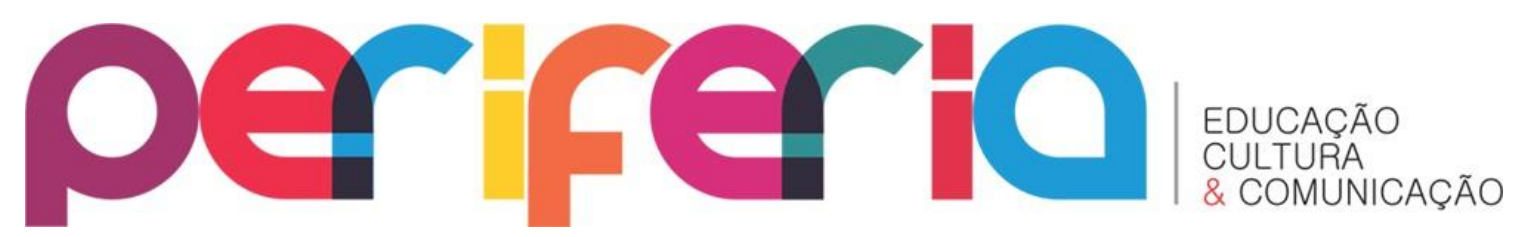

vivida pelos sujeitos que a constituem. No entanto, o autor está atento, também, ao processo de escolha desses símbolos. Anderson, ao citar Ernest Renan, lembra que a base de uma nação consiste em que todos os indivíduos tenham muitas coisas em comum, e também que todos tenham esquecido muitas coisas (ANDERSON, 2008, p. 32). No entanto, ao contrário do que pode parecer, a construção do comum, muitas vezes, não se dá de forma harmônica: sua instituição baseia-se, quase sempre, na supressão e na invisibilidade dos elementos que o colocam em risco. No caso do Brasil, por exemplo, é elucidativo, para entender o processo de instituição do comum, pensar em como ocorreu a instituição do português como língua nacional. Para muitos grupos étnicos, o mencionado processo se constituiu de forma traumática e violenta, marcado por perseguições, silenciamento e esquecimento do que, para alguns, é considerado um dos principais marcadores culturais, a língua (SEYFERTH, 2000).

No campo de estudo sobre a construção do projeto nacional, Eric Hobsbawm também se destaca como uma importante referência. $O$ autor se debruça sobre as estratégias dos Estados nacionais para construção do sentimento de nacionalidade. Ao cunhar o termo tradição inventada, o autor evidencia que as tradições dos séculos XIX e XX são, muitas vezes, inventadas, utilizadas como recursos de construção de unidade nacional e do sentimento de nacionalidade.

Ao refletir sobre as estratégias e os caminhos percorridos pelo Brasil para pensar sua comunidade, história e tradições, esbarramos, inevitavelmente, no debate sobre a mestiçagem. Seyferth (1989) aponta para o fato de a mestiçagem ter (e ainda tem) sido utilizada por muitos como argumento explicativo da realidade brasileira. De acordo com a autora, a figura do mestiço ora aparece como problema, ora como solução. No contexto do projeto cunhado por Coelho Neto, ou seja, nos anos de 1910, percebe-se a valoração da mestiçagem e o fortalecimento de um modo de interpretar as relações entre os grupos étnicos, o que Roberto DaMatta chama de fábula das três raças. Para o autor:

[...] a fábula das três raças se constitui na mais poderosa força cultural do Brasil, permitindo pensar o país, integrar idealmente sua sociedade e individualizar sua cultura. Essa 


\section{periferio}

fábula hoje tem força e o estatuto de uma ideologia dominante: um sistema totalizado de ideias que interpenetra a maioria dos domínios explicativos da cultura. Durante muitos anos forneceu e ainda hoje fornece, o mito das três raças, as bases de um projeto político e social para o brasileiro. (DAMATTA, 2000, p. 69).

Apesar da visível hegemonia branca e do fortalecimento das perspectivas que apontavam o branqueamento como alternativa para a sociedade brasileira, a fábula das três raças manteve-se como um expressivo fator ideológico de interpretação do Brasil pelos brasileiros. Além disso, contribuiu para consolidação da imagem do mestiço como elemento homogeneizador tão necessário ao projeto de construção do Estado-nação.

Um aspecto que também merece destaque no debate sobre a construção do projeto nacional do Brasil é sinalizado por Maria Alice Rezende Gonçalves, que afirma que "a ideia de nacionalidade assume um sentido étnico, em que elementos de origens díspares com uma suposta história em comum aparecem unidos" (GONÇALVES, 1999, p. 30). A afirmação da autora explica e auxilia a pensar o movimento realizado em 1910, que visava tornar a capoeira a ginástica nacional e o esporte essencialmente brasileiro. Nesse sentido, se para algumas perspectivas históricas a capoeira é compreendida enquanto uma manifestação cultural produzida pela diáspora negra, a corrente nacionalista se apropria da manifestação e tenta invisibilizar seus aspectos étnicos, tornando-a um elemento autêntico da cultura nacional.

\section{A EMERGÊNCIA DOS GRUPOS ÉTNICOS NO CAMPO EDUCACIONAL: UMA (RE)LEITURA DO BRASIL?}

A perspectiva sociológica sobre o campo educacional sugere uma forte relação entre a educação e a interpretação que a sociedade faz de si mesma. A partir deste parâmetro, é possível dizer que, na escola - uma das principais instituições de socialização nas sociedades modernas-, encontram-se estruturas, cerimonias e símbolos que refletem e reforçam o que Benedict Anderson chama de comunidades 


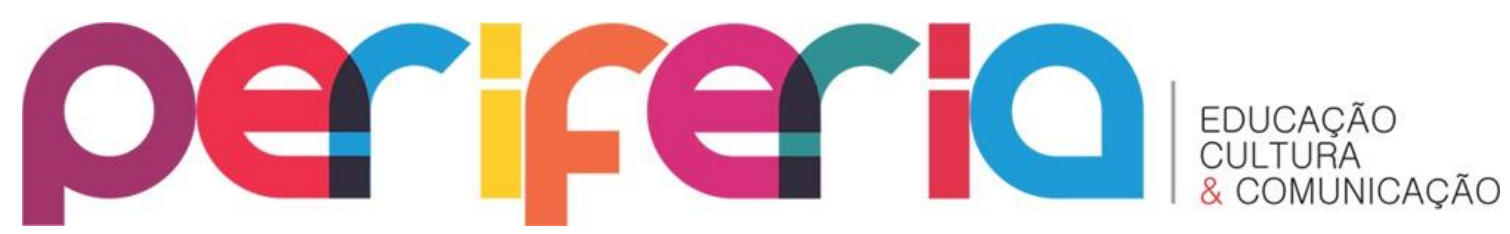

imaginadas, e Eric Hobsbawm denomina de invenção das tradições. Nesse sentido, a análise dos símbolos que estruturam o trabalho escolar, e o exame das políticas públicas educacionais permitem fazer uma leitura do Brasil e da imagem que este cria sobre si mesmo.

O olhar contemporâneo sobre o campo educacional aponta sinais que evidenciam mudanças na forma como o Brasil tem interpretado sua história. Estas mudanças se expressam com a consolidação de instituições como a Secretaria de Políticas de Promoção da Igualdade Racial (SEPPIR), a Secretaria da Educação Continuada, Alfabetização, Diversidade e Inclusão (SECADI) e a Fundação Cultural Palmares (FCP), que passam a desenvolver estratégias e ações políticas focalizadas na valorização dos particularismos. As transformações são anunciadas, também, pela explosão de experiências com políticas de ação afirmativa por todo o território nacional, e pela homologação de Leis como a 10639/03 e 11645/08 ${ }^{6}$, que colocam em evidencia a necessidade de promover e valorizar as minorias ${ }^{7}$ étnicas marginalizadas na/da sociedade brasileira.

Esta nova conjuntura política deve ser compreendida como consequência de uma série de fatores e variantes históricos e sociais. Entre eles, pode-se destacar a atuação do Movimento Negro, que denunciava, desde o século XX, a falácia da democracia racial e a distância entre a realidade social e o mito fundador da nação; a produção de dados pelo Instituto Brasileiro de Geografia e Estatística (IBGE), que, ao incluir a variante cor nas pesquisas realizadas a partir da década de 70 do século XX, permite ao governo brasileiro dimensionar o tamanho e a gravidade da desigualdade racial no país; a conjuntura internacional marcada por conferências de combate ao racismo e promoção da igualdade racial - que é outro fator que pressiona o Estado brasileiro a formular políticas públicas destinadas ao combate à desigualdade entre as

\footnotetext{
${ }^{6}$ Altera a Lei no 9.394, de 20 de dezembro de 1996, modificada pela Lei no 10.639, de 9 de janeiro de 2003 , que estabelece as diretrizes e bases da educação nacional, para incluir no currículo oficial da rede de ensino a obrigatoriedade da temática "História e Cultura Afro-Brasileira e Indígena".

7 O conceito de minoria utilizado neste trabalho visa expressar a sub-representação política da população negra e afro-brasileira. Na atualidade, este grupo étnico compõe mais da metade da população brasileira.
} 


\section{periferio}

populações negras e brancas; e os resultados do Projeto UNESCO ${ }^{8}$, uma série de pesquisas sobre as relações raciais realizadas no Brasil no período de 1951 a 1952. Os resultados e apontamentos das pesquisas desnudam o mito da democracia racial, apontam o racismo como uma variante da sociabilidade brasileira e colocam as relações étnico-raciais como ponto de estudo e pesquisa no âmbito acadêmico (MAIO, 2002).

Nesse contexto marcado por intensas mudanças, a educação torna-se um dos principais focos de ação do Movimento Negro, tendo em vista seu histórico de silenciamento das expressões da cultura afro-brasileira e naturalização da posição de inferioridade do negro na sociedade brasileira. Sobre este ponto, parece interessante o debate sobre estigma travado por Erving Goffman. De acordo com o autor, o estigma se configura pela relação entre atributo e estereótipo, que, em determinadas relações sociais, ganha um caráter distintivo e pode ser utilizado como elemento para discriminação de grupos e sujeitos (GOFFMAN, 1963). Os debates e as pesquisas que se debruçam sobre a escola nesse período evidenciam a existência de práticas pedagógicas que pouco contribuem para autoestima de estudantes negros e negras e denunciam, inclusive, a presença de práticas racistas no ambiente escolar (CAVALLEIRO, 2002), demonstrando ser a cor da pele um aspecto distintivo, ou seja, um estigma.

Este estigma é reforçado por um contexto educacional onde prevalece a noção da superioridade da identidade europeia em relação a todas as outras identidades e manifestações culturais ligadas a elas. Edward Said, ao discutir a construção do imaginário sobre o Oriente como o espaço de negação das pretensas qualidades do Ocidente, dialoga com alguns dos principais conceitos de Gramsci:

\footnotetext{
${ }^{8}$ No contexto pós-holocausto, a Organização das Nações Unidas para a Educação, Ciência e Cultura (UNESCO) busca mostrar ao mundo uma experiência de relações étnico-raciais bem sucedida. O Brasil, devido à sua fama de promotor da democracia racial, é escolhido como laboratório. No período de 1951 a 1952, uma série de pesquisas sobre as relações raciais é realizada no país. Para uma discussão mais aprofundada sobre o Projeto UNESCO, conferir: MAIO, M. C. O projeto UNESCO e a agenda das Ciências Sociais no Brasil dos anos 40 e 50. Revista Brasileira de Ciências Sociais: Peirópolis; Abong, 2002.
} 


\section{periferio}

Gramsci fez a proveitosa distinção entre as sociedades civil e política, em que a primeira é feita de afiliações voluntários (ou pelo menos racionais e não-coercitivas) como escolas, famílias e sindicatos; e a última de instituições estatais (exército, polícia, burocracia central) cujo papel na entidade política é a dominação direta. A cultura, é claro, será vista operando nos marcos da sociedade civil, onde a influência das ideias, instituições e outras pessoas não atua por meio da dominação, mas por aquilo que Gramsci chama de consenso. Em qualquer sociedade não-totalitária, então, certas formas culturais predominam sobre outras, do mesmo modo que certas ideias são mais influentes que outras; a forma dessa liderança cultural é o que Gramsci identificou como hegemonia [...] É a hegemonia, ou melhor, o resultado da hegemonia em ação que confere ao orientalismo a durabilidade e a força sobre as quais estive falado até agora. $O$ orientalismo nunca está longe daquilo que Denys Hay chamou de ideia da Europa, uma noção coletiva que identifica a "nós" europeus em contraste com todos aqueles "não europeus", e de fato pode ser argumentado que o principal componente na cultura europeia é precisamente o que a torna essa cultura hegemônica tanto na Europa como fora dela: a ideia de identidade europeia como sendo superior em comparação com todos os povos e culturas não-europeus (SAID, 1990, p. 18).

É possível dizer, respeitando as especificidades de cada contexto, que as considerações de Edward Said sobre a hegemonia europeia e a construção do imaginário sobre o Oriente podem ser aplicadas para discutir e pensar as imagens tecidas sobre a cultura afro-brasileira no espaço escolar. Tais imagens geralmente reforçam uma tentativa de folclorização das manifestações da cultura afro-brasileira, evidenciando sua veiculação a partir de um olhar colonizador. No entanto, na contramão desta perspectiva hegemônica, é possível encontrar movimentos que apontam a necessidade de forjar imagens valorativas em relação à cultura afrobrasileira. Nesse contexto, podemos identificar a ação de diferentes setores organizados da sociedade civil, sobretudo os movimentos negros, que pressionam o Estado brasileiro a elaborar políticas públicas educacionais que reflitam a importância de valorização do negro e de sua contribuição para história e a cultura brasileira, desafiando a escola a refletir sobre a sua estrutura curricular, a organização do 


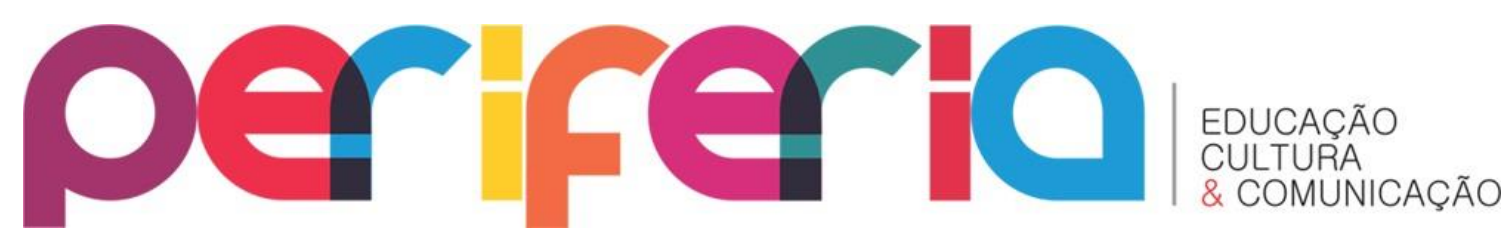

trabalho docente e suas cerimônias, a partir do parâmetro de valorização das diferenças étnicas.

Todo o processo descrito acima se configura como uma mudança paradigmática na maneira em que o Brasil conta e interpreta sua história. A noção de mestiçagem, base homogeneizadora do mito fundador do Estado nacional, vai cedendo espaço, pouco a pouco, para a emergência dos diferentes grupos étnicos e, consequentemente, maior visibilidade aos seus respectivos símbolos culturais. É possível dizer que, de forma pouco linear e em um processo com muitas contradições e embates, o país começa a reconhecer-se enquanto uma nação multiétnica. Maria Alice Rezende Gonçalves e Vinicius Oliveira Pereira apresentam em seu trabalho uma discussão interessante sobre a relação das políticas particularistas e a emergência das novas etnicidades, com destaque para a afro-brasileira:

A entrada nos anos 2000 foi marcante para a institucionalização e visibilidade dos afro-brasileiros como um grupo étnico-racial na esfera pública como também para a construção de novas etnicidades como a afro-brasileira. A proposição de programas e projetos educativos emergiu como nunca antes visto no sistema de ensino nacional. Neste contexto, a lei 10639/03 surge como uma ferramenta para a construção da etnicidade afro-brasileira no espaço escolar. (GONÇALVES e PEREIRA, 2013, p. 34).

Ao longo do artigo, os autores discutem, ainda, a importância do fortalecimento da etnicidade para o exercício da cidadania:

No caso brasileiro, a etnicidade tem servido para a construção dos grupos de afro-brasileiros como grupos visíveis com demandas no campo educacional e em outros espaços da vida pública, que visam o direito à cidadania. Neste contexto, cabe à escola a difusão das culturas produzidas por estes grupos, tornando-os visíveis, reconhecidamente produtores de saberes relevantes para a vida social da nação. É esta a tarefa primordial da lei 10.639/03. (GONÇALVES e PEREIRA, 2013, p. 37).

É nesse contexto de fortalecimento da etnicidade afro-brasileira que a escola passar a (re)pensar e a (re)inventar as tradições e narrativas (re)produzidas no 


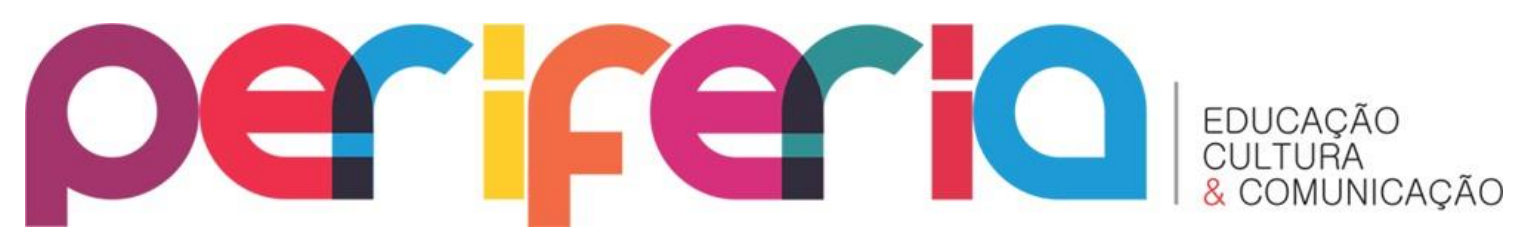

ambiente escolar. Evidencia-se a maior presença de elementos da história e da cultura afro-brasileira nas cerimonias escolares. No Rio de Janeiro, por exemplo, todos os municípios do estado aderem às comemorações do dia 20 de novembro, data de aniversário da morte de Zumbi dos Palmares e dia nacional da consciência negra. A data é marcada por uma série de eventos escolares que relembram o legado de Zumbi e as histórias de luta da população negra brasileira. Apesar das expressivas mudanças, cabe ponderar os desafios desse novo contexto, que perpassam pela produção de materiais didáticos respaldados na valorização dos diferentes grupos étnicos, formação de professoras e professores, e maior comprometimento das secretarias de educação com a promoção da valorização da diversidade étnico-racial. Dessa forma, o processo de enegrecimento do saber e a construção de um país verdadeiramente multiétnico vão tornar-se uma realidade possível e concreta.

\section{A CAPOEIRA NO PROGRAMA MAIS EDUCAÇÃO: PENSANDO OS LIMITES E POSSIBILIDADES DO TRABALHO NO CONTEXTO ESCOLAR}

No decorrer deste artigo, pôde-se observar que a atual introdução da capoeira nas escolas municipais da cidade de Nova Iguaçu ocorre através do Programa Federal Mais Educação. A mencionada manifestação cultural afro-brasileira faz parte do leque de oficinas ofertadas pelo programa, e é oferecida por capoeiristas das diferentes vertentes $^{9}$ da capoeira. A responsabilidade pela escolha do conjunto de oficinas que comporá as atividades do horário integral das unidades escolares cabe à coordenação do Programa Mais Educação de cada escola.

Ao nos debruçarmos sobre os objetivos propostos pelo Programa Mais Educação para a oficina de capoeira, percebemos que eles estão alinhados com as discussões sobre a necessidade de valorizar a contribuição do negro para a sociedade brasileira, na medida em que sinalizam a importância da oficina trabalhar a dimensão histórica da manifestação. Este posicionamento pode significar a construção de novas

\footnotetext{
${ }^{9}$ As mais conhecidas vertentes da capoeira são a capoeira regional, de Mestre Bimba, e a capoeira angola, codificada por Mestre Pastinha.
} 


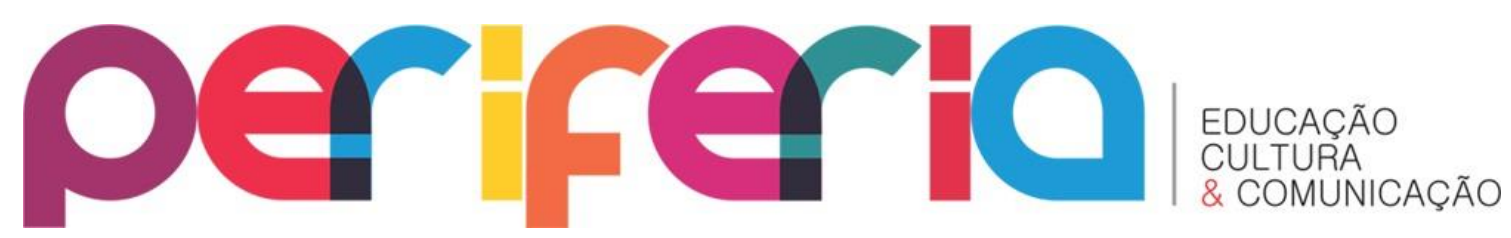

narrativas no ambiente escolar, tendo em vista a possibilidade de apresentar a capoeira como uma manifestação cultural produzida a partir da diáspora negra. Levando em consideração esta perspectiva, tornar-se possível a produção de imagens positivas em relação ao mencionado grupo étnico, pois, a despeito de uma das experiências mais desumanizantes da história da humanidade, os negros e negras conseguiram transformar materiais culturais em novas tradições no novo mundo, preservando, através da (re)invenção, os referenciais de sua cultura (MINTZ e PRICE, 2003).

Tais referenciais baseiam-se no que chamamos, na atualidade, de valores civilizatórios afro-brasileiros. Tratam-se de valores como circularidade, oralidade, musicalidade, ludicidade, memória, religiosidade, energia vital, ancestralidade, corporeidade, entre outros. Tais valores encontram-se presentes na maioria das manifestações da cultura afro-brasileira, e se distinguem de forma contundente dos valores das sociedades ocidentais. A proposta de abordagem da capoeira realizada pelo Programa Mais Educação visa contemplar esta multidimensionalidade de valores, na medida em que propõe um trabalho que leve em consideração os aspectos culturais, físicos, éticos, estéticos, musicais, históricos e sociais da capoeira.

A partir deste parâmetro, pensamos ser possível utilizar o conceito de fato social total para analisar a capoeira no contexto do Programa Mais Educação. De acordo com Mauss:

Os fatos sociais totais exprimem, ao mesmo tempo e de uma só vez, toda a espécie de instituições: religiosas, jurídicas e morais - estas politicas e familiais ao mesmo tempo; econômicas - supondo formas particulares de produção e de consumo, ou antes, de prestações e de distribuição, sem contar estéticas, nas quais desembocam tais fatos e os fenômenos morfológicos que manifestam essas instituições. (MAUSS, 1974, p. 41).

Ao utilizar este conceito, o autor francês se referia ao "Kula", um comércio intertribal praticado por nativos das ilhas de Trobriand, onde circulavam coisas economicamente uteis, bem como pessoas, gentilezas e eventos sociais. Para os 


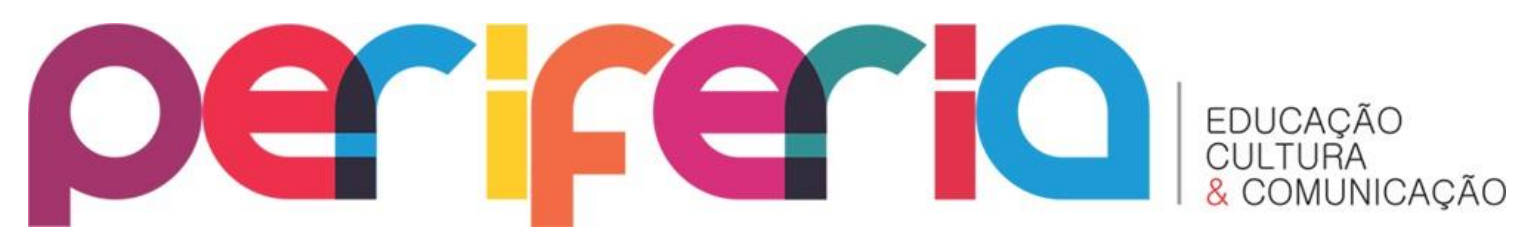

trobriandeses, a vida econômica, social e religiosa era indivisível, ou seja, o fato social era total. Mauss (1974) destaca que os fatos sociais totais não são exclusividades dos trobriandeses, pelo contrário, podem ser encontrados em todas as sociedades. Nesse contexto, a capoeira, considerada patrimônio cultural imaterial e manifestação afrobrasileira, reúne elementos que demonstram ser ela um fato social total. A partir e através desta manifestação, são constituídas relações onde acontecem trocas de saberes, sentidos e histórias. Tais relações baseiam-se na circularidade que tem sua maior expressão na formação da roda, presente nas mais diferentes manifestações de matriz africana. A multidimensionalidade da capoeira reforça a ligação com a ancestralidade africana, onde, assim como em Trobriand, a vida é vivida em sua totalidade.

O conceito maussiano foi aplicado na análise de diferentes manifestações culturais afro-brasileiras. Gonçalves (2009), por exemplo, aponta o samba como fato social total, identificando suas múltiplas facetas. De acordo com a autora, por meio do samba formam-se extensas redes de solidariedade e reciprocidade responsáveis pela pacificação dos costumes e pela resistência e continuidade da cultura afro-brasileira (GONÇALVES, 2009, p. 142). A autora corrobora sua tese ao identificar no âmbito do samba as múltiplas facetas que se manifestam nos planos político, econômico, religioso, psicológico. Quando pensamos a capoeira a partir do parâmetro da multidimensionalidade, podemos identificar em sua composição elementos que corroboram a tese de que esta manifestação também é um "fato social total". A capoeira se manifesta em um campo onde se descortinam diversas dimensões - como a simbólica, política e econômica-, responsáveis pela constituição de redes que promovem trocas entre diferentes pessoas. É a partir da possibilidade de explorar estas múltiplas facetas que acreditamos ser possível a colaboração do Programa Mais Educação para implementação da Lei 10639/03.

No entanto, como todo processo de transformação educacional, o atual diálogo entre a escola e capoeira é marcado por possibilidades e desafios. Apesar das promissoras possibilidades de trabalho com a capoeira a partir do Programa Mais 


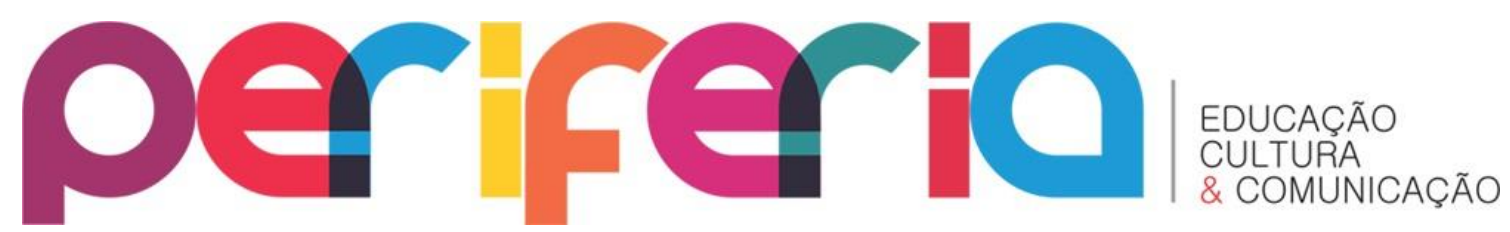

Educação, verifica-se, também, a existência de alguns aspectos que podem prejudicar ou dificultar os trabalhos a serem desenvolvidos. De início, cabe ressaltar os baixos valores pagos aos oficineiros (capoeiristas). De acordo com o documento que regula as atividades do programa:

A atividade do monitor deverá ser considerada de natureza voluntária, na forma definida pela Lei no 9.608 de 18 de fevereiro de 1998, e o ressarcimento das despesas deverá ser calculado de acordo com o número de turmas monitoradas. (BRASIL, Manual Operacional de Educação Integral, 2012, p.11).

Isto significa dizer que os oficineiros que trabalham com o Programa Mais Educação recebem mensalmente uma ajuda de custo para oferecer as atividades no contra turno escolar. Nas escolas públicas urbanas, o valor destinado ao ressarcimento do monitor é de $\mathrm{R} \$ 80,00$ por turma, podendo este acumular até 5 turmas, totalizando o valor de $\mathrm{R} \$ 400,00$ mensais.

No contexto de uma cidade localizada na Região Metropolitana do estado do Rio de Janeiro, o valor destinado ao pagamento dos monitores parece insuficiente até mesmo para arcar com os custos com transporte. Esta situação gera, de acordo com a coordenação do programa nas escolas, uma grande rotatividade de oficineiros, o que dificulta a realização de um trabalho mais homogêneo, contínuo e, por vezes, inviabiliza um diálogo mais aproximado entre oficineiros e o corpo docente, fato que permitiria a construção de práticas educativas mais integradas no contexto escolar. 0 baixo valor destinado à remuneração dos monitores coloca em dúvida a importância dada a um projeto que se propõe a instituir a organização curricular na perspectiva da Educação Integral na educação básica, e diminui a potencialidade de um trabalho mais qualificado, que permitiria a construção de propostas pedagógicas para consolidação da cultura afro-brasileira no espaço escolar.

A análise do documento que regula o Programa Mais Educação permite apontar, ainda, outro curioso ponto. No tópico destinado a sugestões de itens para aquisição de materiais de apoio às oficinas, verifica-se, no campo voltado a capoeira, 


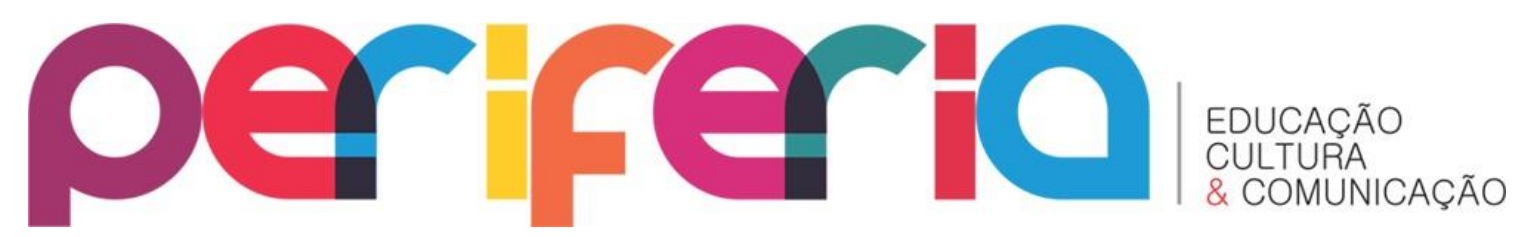

os seguintes materiais: caxixi (instrumento musical), pandeiro, agogô, camiseta de malha fio 30, berimbau completo e calça de capoeira branca. Chama atenção a presença do último item na lista de materiais. No universo simbólico da capoeira, a calça branca está geralmente ligada à capoeira regional, que é conhecida por valorizar os aspectos esportivos da manifestação, em detrimento de outros elementos que a constituem. Há a possibilidade de a escolha ter se dado de forma aleatória. No entanto, quando olhamos para o espaço escolar, notamos a presença mais recorrente desta vertente da capoeira. É possível dizer que em um contexto ainda marcado pela intolerância a alguns elementos da cultura afro-brasileira, o esvaziamento do conteúdo étnico da capoeira é um dos fatores que facilita seu trânsito no mundo escolar.

Este esvaziamento étnico perpassa pela construção de uma abordagem que visa reforçar o caráter esportivo da capoeira. A análise dos discursos veiculados pelas coordenações do Programa Mais Educação nas escolas municipais de Nova Iguaçu aponta para uma tentativa de apresentar a capoeira aos pais e alunos como um esporte. Nessa pesquisa, percebemos que este posicionamento busca se contrapor à visão que aponta ligações entre a capoeira e as manifestações da religiosidade afrobrasileira, sobretudo quando percebe-se a presença de instrumentos como o atabaque em ambas as manifestações. Acreditamos que esta preocupação também está presente no Programa Mais Educação, tendo em vista que o atabaque não consta como um dos itens financiáveis do Programa.

\section{CONSIDERAÇÕES FINAIS}

A atual proposta de introdução da capoeira no espaço escolar coloca em evidencia as mudanças sobre os quais o campo educacional tem passado. Tais transformações, que nesse artigo são compreendidas como resultados da organização e da pressão política dos diferentes setores da sociedade civil, têm apontado a necessidade de valorização dos patrimônios, símbolos, histórias e referenciais dos diferentes grupos étnicos que constituem a sociedade brasileira. A análise da proposta realizada pelo Programa Mais Educação expressa, de certa forma, a tessitura 


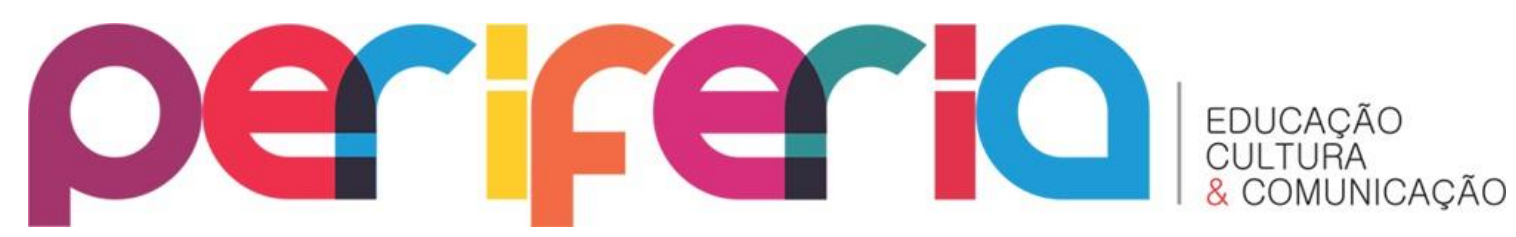

constituída por estas discussões. A abordagem do trabalho tem potencialidade para a consolidação do reconhecimento da contribuição do negro para a sociedade brasileira, tendo em vista, sobretudo, a orientação de trabalhar com a história da capoeira, que reúne uma série de narrativas sobre o poder e a resistência dessa manifestação afrobrasileira.

Cabe destacar, também, a importância da proposta de uma abordagem multidimensional da capoeira no espaço escolar. Este posicionamento vai ao encontro dos debates travados no campo dos estudos sobre cultura afro-brasileira, que sinalizam a importância da valorização e reconhecimento das especificidades das manifestações da cultura afro-brasileira, que reúnem, em sua grande maioria, elementos como musicalidade, oralidade, circularidade e ancestralidade, responsáveis por sua manutenção e preservação até os dias atuais. Na medida em que a escola assume esta perspectiva de abordagem, acreditamos que ela colabora para implementação das ações de salvaguarda da capoeira, considerada atualmente patrimônio cultural imaterial do Brasil (BRASIL, 2007).

Nossa pesquisa aponta, ainda, dificuldades e resistência a alguns elementos da cultura afro-brasileira, sobretudo quando estes estão ligados ao universo simbólico das religiões de matriz afro-brasileira. Percebemos a tentativa de esportização da capoeira como uma estratégia escolar para desenvolver o trabalho em um espaço marcado pela intolerância religiosa. Este posicionamento, apesar de aparentemente resolver a situação, não dá conta da necessidade de se discutir na instituição escolar os problemas ligados à intolerância religiosa.

Os desafios em relação à proposta do Programa Mais Educação para introdução da capoeira no espaço escolar perpassam, também, pelo baixo orçamento destinado à remuneração dos oficineiros. Esta situação tem sido um dos fatores que prejudica o desenvolvimento do trabalho com a capoeira, tendo em vista a grande rotatividade gerada pela baixa remuneração. A construção de práticas pedagógicas valorativas dos referenciais afro-brasileiros demanda um comprometimento do corpo docente e dos demais sujeitos envolvidos nesse processo, e a fragilização das relações desses sujeitos 


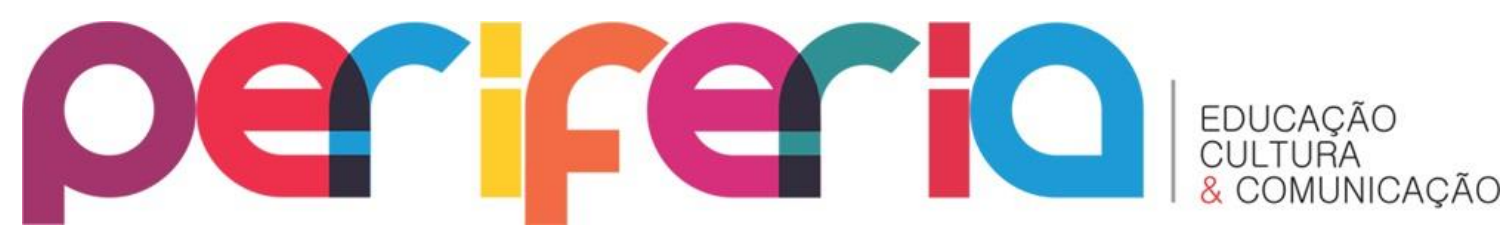

com o ambiente escolar, decorrente da baixa remuneração, pouco contribui. Ao contrário, colabora para a construção de um trabalho pouco orgânico no contexto escolar.

\section{REFERÊNCIAS BIBLIOGRÁFICAS}

ANDERSON, B. Nação e Consciência Nacional, São Paulo: Àtica, 1989.

BRASIL. Dossiê. Inventário para registro e salvaguarda da capoeira como patrimônio cultural do Brasil. Instituto do Patrimônio Histórico e Artístico Nacional / Ministério da Cultura - Brasília: MEC, 2007.

. Lei de Diretrizes e Bases da Educação Nacional (Lei no 9.394 / 96). Diário Oficial da União, Brasília, DF, 20 de dezembro de 1996.

. Lei no 10.639/03, De 09 de janeiro de 2003. Diário Oficial da União, Brasília, DF, 10 de janeiro de 2003.

- Manual Operacional de Educação Integral. Diretoria de Currículo e Educação Integral / Secretaria de Educação Básica / Ministério da Educação - Brasília: MEC/SEB, 2012.

CAVALLEIRO, E. Do silêncio do lar ao silêncio escolar. Racismo, preconceito e discriminação na educação infantil. São Paulo: Contexto, 2003.

DA MATTA, R. A. Relativizando - uma introdução à antropologia social. Petrópolis: Vozes, 2000.

GOFFMAN, E. Estigma: notas sobre a manipulação da identidade deteriorada. Rio de Janeiro: LTC, 1988 (capítulo 1)

GONÇALVES, M. A. R.; PEREIRA, V. O. O contexto histórico das políticas racializadas e a emergência de novas etnicidades. $E$ a emergência do discurso racializado no sistema de ensino: as possibilidades e desafios da Lei 10639/03. Revista TEIAS. V14, n. 34, 2013, p. 33-48.

GONÇALVES, M. A. R. Brasil, meu Brasil brasileiro: notas sobre a construção da identidade nacional. In:

(org.) Educação e cultura: pensando em cidadania, Rio de Janeiro, Quartet, 1999: 17-42.

O samba é o dom: notas sobre o samba como fato social total e a educação escolar. In: SISS, Ahyas. MONTEIRO, A. J. J. (org.) Educação, cultura e relações interétnicas, Rio de Janeiro, Quartet e Edur UFRRJ, 2009, p. 127-143.

HOBSBAWM, Eric; RANGER, Terence (orgs). A Invenção das Tradições. Rio de Janeiro: Paz e Terra, 1984.

MAIO, M. C. O projeto UNESCO e a Agenda das Ciências Sociais no Brasil dos anos 40 e 50. Revista Brasileira de Ciências Sociais. V. 41. São Paulo. Oct. 1999.

MAUSS, M. O ensaio sobre a dádiva: formas e razão de troca nas sociedades arcaicas. In: . Sociologia e antropologia, v. 2, São Paulo: EPU, 1974.

PEREIRA, V. O. A capoeira no cotidiano escolar: tecendo caminhos para implementação da lei no 10639/03. In: GONÇALVES, M. A. R.; RIBEIRO, A. P. P. G. A. (Org.). Diversidade e Sistema de Ensino Brasileiro. 2ed. Rio de Janeiro: Outras Letras Editora, 2014, v. 2, p. 107-119. 


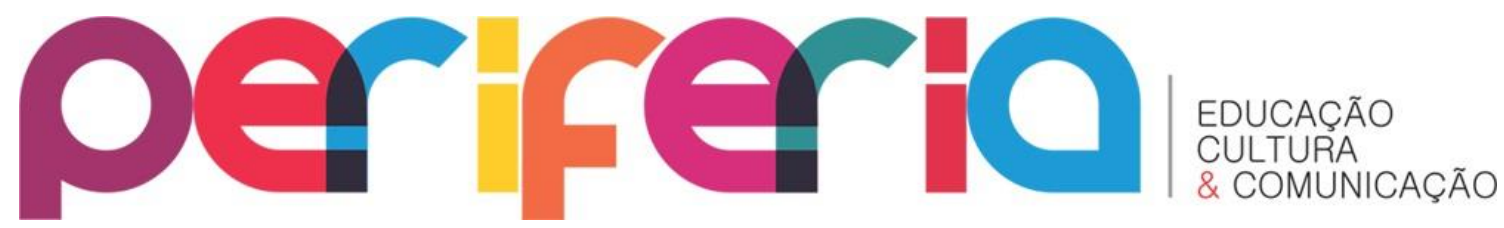

SEYFERTH, Giralda. As Ciências Sociais no Brasil e a Questão Racial. In: Cativeiro \& Liberdade. UERJ. Rio de Janeiro, 1989.

As identidades dos imigrantes e o melting pot nacional. Horiz. antropol., Nov 2000, vol.6, no.14, p.143-176.

SAID, E. W. Orientalismo: o Oriente como invenção do Ocidente. Trad. Tomás Rosa Bueno - São Paulo: Companhia das Letras, 1990.

SIDNEY, W. M.; PRICE, R. O Nascimento da Cultura Afro-Americana - uma perspectiva antropológica. Trad. Vera Ribeiro - Rio de Janeiro: Pallas: Universidade Cândido Mendes, 2003. 